\title{
Les ciutats del cavaller Martorell. La representació de l'urbs en el Tirant lo Blanc
}

\section{The cities of the knight Martorell. The representation of the city in Tirant Lo Blanc}

\author{
TEResa IZquierdo Aranda \\ teresa.izquierdo@uv.es \\ Universitat de València
}

\begin{abstract}
Resum: El Tirant lo Blanc és fruit d'experiències personals de Joanot Martorell. L'escriptor projecta en la novel la una fina mirada al seu temps i, per a traslladar-ho amb vivesa, empra tota la realitat com a instrument de treball, atorgant al corpus de l'obra un vitalisme renovador. El paisatge urbà és l'escenari que forneix la ficció, que complementa la vitalitat psicològica dels protagonistes i enriqueix el seguit dels fets i històries narrades. Esdevé un recurs estètic que permet a l'escriptor enllestir la trama i guiar la imaginació del lector per l'univers en què es desenvolupa la gesta. El present article analitza la descripció literària de la ciutat per l'escriptor, les seues consideracions estètiques del paisatge urbà per descobrir quina era, en definitiva, la seua percepció del fenomen urbà.
\end{abstract}

Paraules clau: Tirant lo Blanc, Martorell, descripció, literatura medieval, ciutat medieval.

\begin{abstract}
Tirant lo Blanc is the result of Joanot Martorell's personal experiences. The writer projects in the novel a fine look at his time and, to move it with liveliness, he uses all reality as a working instrument to give to the corpus of the work a renewal vitality. The urban landscape is the scene that complets the narration, which complements the psychological vitality of the protagonists and enriches the series of events and stories told. It becomes an aesthetic resource that allows the author to complete the plot and guide the reader's imagination for the universe in which the deed takes place. This article analyzes the literary description of the city by the writer and his aesthetic considerations of the urban landscape to discover what his perception of the urban phenomenon was.
\end{abstract}

Keywords: Tirant lo Blanc, Martorell, description, Medieval literature, Medieval city. 
Teresa Izquierdo Aranda. Les ciutats del cavaller Martorell. La representació de l'urbs en el Tirant lo Blanc

\section{Introducció: forma de descriure y fonaments de la descripció}

La personalitat de Tirant lo Blanc va ser creada en la tradició de fantasia i idealisme èpic del conegut roman francès dels segles XII i XIII, que trobaria una acollida grata en un entorn aristocràtic àvid de lectures que el submergiren en el món de somnis dels grans herois de l'Antiguitat. Molts eren les llinatges que buscaven un origen en la història o la mitologia per a atribuir-se sense cap pudor un avantpassat gloriós (Riquer 1990). La literatura va saber respondre a les necessitats psicològiques del moment creant un protocol d'actuació, de caràcters i actituds que abastava des dels afanys de dominació als recels davant una força enemiga (Riquer 1992).

És en aquest sentit on cobra tot el seu significat el terme erre, viatge o camí, no gaire emprat en la literatura catalana, si podem distingir l'evocació de errant que ens lliura indefectiblement als peus de la natura, el paisatge, l'espai. Tot i que el Tirant lo Blanc se separa del llibre de cavalleries en sentit clàssic, en considerar el seu protagonista com un chévalier errant no podem defugir de considerar la natura i l'ambient com uns dels agents més determinants per a l'elaboració de la ficció novel lada. El paisatge esdevé, aleshores, un recurs estètic omnipresent, que permet a l'escriptor enllestir la trama argumental al temps que guiar la imaginació del lector pel cosmos -real o imaginari- en què es porta a cap la gesta.

Diem real o imaginari perquè, des que Riquer va encertar a distingir el Tirant lo Blanc com una novel la cavalleresca -no pas un llibre de cavalleries-, el positivisme anirà guanyant terreny a l'element fantàstic, per obrir la porta al món contemporani que envolta l'autor. Al Tirant es fonen ambdós conceptes amb una harmonia sorprenent, l'idealisme medieval i el vitalisme modern denuncien la ubicació de la novel la al trànsit de dues nocions ben diferents del món i de la relació de l'home amb la natura que l'acarona. Martorell intueix l'adveniment d'una renovació arronsant i, dotat d'un agut sentit de percepció, projecta una fina mirada al seu temps, mirant de recuperar per a la memòria la seua collita més rica, conscient d'assistir a l'albada d'un nou horitzó (Gadea i Cònsul 1990: 5). Per a traslladar-lo amb vivesa empra la realitat com a instrument de treball, lliure de prejudicis, escrúpols i exclusions, encapçala, en paraules de Vargas Llosa (1991: 2535), l'estirp d'autors que pretenen crear a les seues novel les una «realitat total». Es delita en la descripció de cada espai, de vegades delinea amb exactitud el paisatge i descobreix el gust per la factura acabada per a crear una realitat paral lela perfectament assimilable. El recrea amb un llenguatge quotidià, plantejat amb la disciplina d'una lent òptica que tant prompte capta globalment l'entorn, com el recrea amb lleugeres pinzellades amb una minuciositat semblant a la pintura flamenca dels van Eyck o la prosa de Chastellain. D'altres, en canvi, proporciona ràpids tocs de color sols per dibuixar l'espai pel qual viatja la nostra imaginació, de manera que l'espai així comprés és sempre controlable. Hereu de l'esperit de l'última Edat Mitjana, pondera un caràcter visual en esprémer les possibilitats dels recursos expressius per crear una imatge òptica. La ficció és percebuda directament i exacta, amb un naturalisme vivaç (Huizinga 1984: 410-419). Per a gaudir de la lectura, és necessari rendir-se al sensualisme insinuat, oblidar-se d'anàlisis estilístics, semàntics, 
de la recerca de fonts i deixar-se seduir per l'univers suggerit, on o la vista, l'olfacte, el tacte, l'oïda o fins i tot el gust estan ben servits.

El paisatge urbà és l'escenari que forneix la trama, que complementa la vitalitat psicològica dels protagonistes i enriqueix el seguit dels fets i històries narrades. Assisteix constant, però no de manera passiva, combrega amb els sentiments dels personatges, d'una forma passiva, s'erigeix en sinònim d'emoció i d'acció, assumint un paper complex en el nucli argumental. Serveix a l'autor per explorar noves vies expressives, ampliar els seus registres estètics, travar simbolismes o simplement recrear-se en la seua descripció, per imprimir a la narració el ritme desitjat.

A partir de descripcions de valls, muntanyes, places, castells, fonts, ports, etc. delinea la varietat d'escenaris pels quals transcorre la trama. Ciutats reals, imaginades o improvisades són descrites amb uns criteris de versemblança que per la seua similitud resulten familiars. Les descripcions són sempre senzilles, basades en una selecció de paràmetres concrets perquè la visualització escènica siga immediata. Es conformen a partir d'una suma de persones, edificis, ornaments, arbres, rius, animals afegits amb el tacte del perfeccionista que entén cada detall com un element imprescindible per orientar el lector.

Des dels seus inicis a Anglaterra, fins Constantinoble, recorre escenaris familiars a la noblesa de la Corona de Aragó, que era qui en definitiva tindria accés a la lectura. Territoris explorats i verificables, en els quals situa guerra, amor, maldat, ironia, lluites de poder i comicitat, combinades amb credos, rituals, ensenyaments, gustos i creences. No refusa cap vessant d'una vida suggestiva i contradictòria amb la qual, lluny de frustrar la cohesió estilística, la convergència d'aspectes tan diversos transmet als paisatges una credibilitat inusitada, estrenyent el teixit argumental amb la coherència d'un manual. Una espècie de compendi «útil», com encerta a definir Escartí (2005: 12), per a l'oligarquia urbana, l'aristocràcia, el clergat. Aquesta component verista entalla la major part dels paisatges al Tirant: des de vastes superfícies fins a recintes íntims, al repertori trobem paisatges urbans, campestres, marítims, interiors arquitectònics.

Conscient que la versemblança requeria àmbits creïbles, el medi circumdant contextualitza l'argument, atorgant al corpus de l'obra un vitalisme renovador. Trasllada la varietat escènica apreciable a l'orde quotidià, per conjugar-la amb fórmules estilístiques de redacció i de descripció deduïdes de l'experiència sensorial. Res més lògic per fer assimilable la llegenda, que proporcionar al lector un espai que puga aprehendre sense conflictes, amb la mateixa senzillesa que l'entorn real ordinari i al temps tota la seua complexitat, sòlidament fundada en una realitat autèntica, és un vertader document de l'època (Riquer 1990: 218).

Manzanaro (1998: 113-114) estima en Tirant lo Blanc un «camí d'amenitats que s’ha de recórrer individualment» on, tot i l'acusada revolució que causà al seu gènere, destaquen encara molts temes medievals. Susceptible d'ésser percebut pels sentits, calculat i mesurat segons cànons d'abast humà, a la novel la les descripcions són acurades, fornides per una simple enumeració més o menys gruixuda 
de components -sembla un mètode rudimentari en la seua elementalitat i, per açò, justament comprensible i legítim. En la descripció arquitectònica denota un alt grau de documentació, ben informat dels monuments i infraestructures urbanes, l'aparença dels quals actualitza constantment en funció del transcórrer de la jornada. D'acord amb l'ambient evocat, varia l'escena urbana amb la instal lació de cadafals, tarimes i arquitectures efímeres, i fins i tot per la presència de gents que ballen, desfilen o fan cua, perquè aquests són els vertaders agents constitutiu del paisatge.

La nostra imaginació es delecta davant les esplèndides viandes dels convits o arrupeix el nas en percebre la pudor dels cadàvers amuntegats al terra. Mitjançant la imatge, la recreació ambiental brolla, impactant en la seua espontaneïtat; invoca els sentits per conformar un àmbit verídic, garantint l'assimilació de la trama. Enlaira vibracions de la música, tocs de trompetes i campanes, discursos, rebombori o sorprèn amb el silenci. La sonoritat particular de cada llengua caracteritza el paisatge. La paraula proclamada als camps de batalla ressona vigorosa en boca del Capità per insuflar valor, poderosa arma política en ambaixades, fins i tot llegida o murmurada en les oracions. El llenguatge en el Tirant és una font inesgotable de felicitat, instrument primordial del ritu, matèria amb què es fabriquen els actes, que fonamenta els sentiments (Vargas Llosa 1991: 59).

\section{La comprensió de la ciutat per Joannot Martorell}

Martorell crea un univers d'aventures en el qual Tirant recala en més d'un centenar de ciutats, viles, «llocs reals», castells, diferents unitats de població que refereixen certament distints conceptes. Així, en intentar analitzar l'urbs en la novel la, cal precisar què entén l'autor per ciutat i quins són els criteris que guien les seues descripcions perquè, en veritat, més que per a precisar un entorn concret, usa el vocable como una indicació categòrica per assenyalar al lector davant quin tipus de nucli habitat es troba. Martorell concep l'urbs como un espai definit i ben delimitat, que exerceix un domini sobre ella mateixa i sobre el territori circumdant. La ciutat implica concentració de gents i intercanvi d'idees i de productes, a partir del mercat i de les seues funcions comercials (Zambrano 2000: 131-132).

De major o menor entitat i extensió, les urbs són vertebradores de les vies de comunicació, s'erigeixen en punts neuràlgics per al control del territori, i des d'allí es trameten correus «per camins, viles, llocs reals, ports de mà», de manera que el tràfic d'interrelacions és sempre fluid (Pinol 2010: 153). Pel seu poder de consum, per a l'abastiment de la ciutat és fonamental la dinàmica relació que s'estableix entre el camp i la metròpoli a nivell econòmic i productiu (Boucheron, Menjot y Boone 2010: 153). D’ací la imperiosa necessitat de conèixer el territori, perquè el coneixement de la terra és una arma poderosa, valorada en la novel la com una font inestimable de saviesa.

Un aspecte fonamental de la ciutat per a l'escriptor són els seus atributs, els elements que la distingeixen i la fan única, tant siguen de caràcter arquitectònic i monumental, com històric o mític. La referència a cada urbs ve sempre acompanyada d'uns matisos que poden resultar pintorescos, 
però mai exempts d'intencionalitat. Singularitats que deriven sovint de la possessió de relíquies, com a Canterbury, on indica que jeu el cos del patró, Sant Tomàs, precisió innecessària per a la trama, però que Martorell aprofita per il lustrar al lector i aprofundir en la comprensió de l'entorn on es situa l'acció. Orienta amb àgils tocs, recopilant dades de les fonts més diverses, incidint en la singularitat de cada nucli per imprimir-li un segell particular i exclusiu que el faça únic, tret característic de la societat urbana medieval (Narbona 2017: 73-74). Per exemple, «Andrinople» o Adrianòpoli, «abundosa de delits innumerables», és referida com la pàtria d'Aristòtil (Hauf 2005: 1465). Amb un decidit to de lloança, es fa ressò de la justificació històrica que constitueix la qualitat principal de la identitat i la cohesió urbana de la actual ciutat turca d'Edirne (Riquer 1992: 140). El vast i variat repertori de cites incloses en la novel la, enriqueix la narració, i així la ficció resulta fins i tot més creïble.

Característica en el relat és doncs la recreació de paisatges urbans, als quals aplica una determinada coloració ambiental per evocar el context. Als capítols de les campanyes de Tirant a la part septentrional d’Àfrica, els matisos cobren un paper especial. Si als capítols europeus dibuixa praderies, paisatges de muntanya i rius, al Marroc, Alger, Trípoli i Tunis els escenaris són la costa, els arenals $i$ les urbs populoses. Tot i que Martorell no sabem si viatjà mai a un país africà, els traça amb preciosisme, ajustant-se en grans línies a la geografia africana dels segles XIV i XV, establint una sèrie de pautes genèriques sobre el marc polític $i$ administratiu a manera d'orientació. Dibuixa un món oriental dissenyat a partir d'una consulta de cartes geogràfiques i diplomàtiques, a les quals suma testimonis orals i fins i tot literaris de l'època (Rubiera 1993: 18-20). Tot i l'ambigüitat de les descripcions, en el context general que esbossa, les ciutats no deixen de ser entitats caracteritzades per un sistema d'edificacions que fan evident les relacions entre les funcions administratives i els interessos públics i els privats.

En Tlemecén, el vocable ciutat designa una unitat de població fortificada, per a la qual no descriu una tipologia urbanística precisa, sinó que proposa nocions simbòliques de refugi i de resistència. Evoca una urbs emmurallada, envoltada per una extensa horta, amb la ciutat i la vall del voltant perfectament delineades: sols falta aplicar una coloració ambiental que el lector endevina similar a la valenciana i, per tant, accepta sense traves (Giner, Montesinos i Martí 1990: 58). A les urbs mediterrànies o del litoral africà, apel la amb freqüència a hàbitats similars a paratges valencians com la Valldigna o la Murta, familiars al lector de l'època i pròxims a les possessions de l'escriptor, on la presència morisca marcava una forta empremta (Roca Traver 1952: 122-123). En aquest sentit s'entén la menció de tipologies urbanístiques com el «Rafal» en les immediacions Tunis, amb el qual potser evoca la seua alqueria de Ràfol de Xaló (Villalmanzo i Chiner 1992: 34-35), emprada a la novel la per a suggerir la vila rural dedicada a l'explotació agropecuària, cèl lula productiva característica de l'època islàmica a València i Mallorca (López Elum 2003: 66-70). Associada a aquestes nocions, la dieta s'entén també com un dels aspectes que tipifiquen l'escena urbana, com ara quan es fa un repartiment de provisions, o quan es reactiva l'activitat de les botigues, repletes d'aliments propis de l'àmbit mediterrani, «blat, vins, olis, carns salades, mels e llegums». 
Un altre element essencial en la caracterització és la raça, a Caramèn, «en la fi de Barberia qui afronta ab los negrins, çò és ab lo rei de Borno»: la característica principal és el color negre de la pell de les seues gents. que tant fascinava als europeus (Zumthor 1994: 254). Situada en la frontera, és una «ciutat molt gran e fortíssima, ben murada e vallejada, e molt ben fornida de vitualles com de cavalleria». Els criteris amb què considera la ciutat es basen en valoracions pràctiques de superfície, demografia i capacitat d'avituallament i de defensa. En veritat aporta informacions ambigües, perquè, darrere de la imprecisió, s’amaga un escàs domini de la realitat i, per no trair la seua vocació de cronista, es limita a proporcionar dades que sap limitades però segures. Tirant conquista urbs on Martorell menciona santuaris i relats fabulosos per a imprimir-hi el segell particular, sense entrar, però, a descriure-les amb detall.

Ara bé, llevat de Constantinoble, en poques ocasions trobem en la novel la descripcions ajustades de les ciutats que visita el protagonista. L'ambigüitat en les precisions es deu en part a la intencionalitat explícita de l'escriptor de no frustrar la versemblança del relat, de manera que apel la reiteradament a un "per no donar prolixitat", per evitar entrar en detalls que revelarien el seu desconeixement efectiu de l'entorn. Tot i això, la impressió generada al llarg de la novel la reflecteix les dificultats de captació del fenomen urbà. Home de la seua època, en el moment d'atorgar un qualificatiu propi a un lloc habitat, tria un vocable o un altre en funció de la seua personalitat jurídica, la seua topografia, la densitat de la seua població i el predomini de les funcions comercials sobre les activitats agropecuàries (Dutour 2004: 27-33). Distintiva d'una ciutat és la concentració dels símbols de poder i, sobre tot, la identificació de una sèrie d'elements, tals com el palau reial, l'església catedral, el castell, la plaça i la muralla.

\section{Espais de poder: els palaus}

La ciutat constitueix, fonamentalment, un espai de poder. La residència del monarca en una ciutat determinada la converteix en capital del regne, de la qual depenen totes les viles i els castells adscrits a la seua jurisdicció (Jehel i Racinet 1999: 348). A tall d'exemple, Londres és un esplèndid escenari on s'allotja la cort, centre burocràtic i punt neuràlgic de la vida cortesana. El terme palau reial es reserva exclusivament per a la residència del monarca i s'estén a totes aquelles edificacions amb privilegi regi expressament atorgat. No defineix el palau a partir d'una tipologia arquitectònica, sinó per la seua magnificència, perquè a l'autor allò que li interessa és incidir en l'excel lència dels escenaris per els quals transita Tirant.

En relació amb la dotació de l'urbs, amb mínimes indicacions adverteix de l'estratificació social pròpia d'un entorn urbà. En la novel la, la riquesa d'una ciutat es pondera per la sumptuositat dels seus edificis, pel nombre del seus habitants, l'abundància i varietat de les seues gents, la quantitat de comerciants i visitants estrangers. En conseqüència, Londres és descrita com una urbs extraordinària i populosa en la seua excepcional pluralitat de mercaders, artesans i forasters. 
En els capítols anglesos, el rei transita a cavall pels carrers fins la plaça central, imprimeix autoritat al temps que assenyala l'organigrama urbanístic (Oleza 1992: 325). La primera parada és la plaça, on l'esperen els tres estaments socials característics d'una urbs, definits per Eiximenis (1340 c.1409 c.) al Dotrè llibre del Crestià, conforme a les funcions que exerceix cadascun a la ciutat, és a dir, generosos, gentilhomes (juristes, notaris, mercaders) i menestrals.

Certament, la millor descripció del palau es troba a Constantinoble, on una nova demanda d'auxili portarà a Tirant a convertir-se en l'encarnació del cavaller ideal de l'Europa cristiana del segle XV (Izquierdo 2013). Martorell no va elegir Constantinoble a l'atzar: la seua desfeta a mans turques, el 29 de maig de 1453, va conferir al relat una insospitada actualitat (Badia 1993: 40). Metàfora dels afanys cristians, l'escriptor s'informà acuradament de l'organització del territori, de les infraestructures i dels edificis urbans, de les característiques del paisatge i l'orografia per enllestir una ficció creỉble i assimilable, tot $\mathrm{i}$ que les distorsions històriques són una crida incessant a la prudència (Riquer 1990: 167-168). La defensa de Constantinoble s'havia convertit en un tòpic literari del qual ja es feia ressò el Guy de Warwick dos-cents anys abans de la caiguda definitiva de l'Imperi, en 1453 (Riquer 1984: 370-371). Per a la seua descripció, Martorell tindria present el testimoni de Pedro Vázquez de Saavedra, el qual participà en el contingent d'ajuda organitzat pel duc Felip el Bo de Borgonya, en resposta a la crida d'auxili arribada des de Roma (Riquer 1992: 118).

A Constantinoble, Martorell descarta la residència de la família imperial al palau de Blanquernes al nord-oest de la ciutat, que hauria estat la legítima, en l'època evocada a la novel la, en constituir la residència dels Comnenos des del segle XI. En canvi, l'acomoda en l'anomenat Sagrat Palau Imperial, el superb conjunt d'edificacions fundat per Constantí, símbol de l'època d'esplendor de l'Imperi Oriental, per a ennoblir així les gestes del seu protagonista. Recupera conscientment l'antic recinte palatí com a testimoni de la Nea Roma Constantinopolis que, des de la seua fundació en el 324, s'havia erigit en un centre arquitectònic de primer ordre i que representava en Occident un símbol de la riquesa cultural de l'Imperi Bizantí (Krautheimer, 1984). Símbol de l'època d'esplendor per a major transcendència de les gestes de l'heroi, els prodigis dels palaus constantinopolitans havien esdevingut un tòpic nodrit en la tradició dels Mirabilia Urbis Romae i llibres de pelegrinatges com Le Pèlerinage de Charlemagne (Hauf 2005: 488). Situat en les immediacions del port, des d'allí l'Emperador camina fins al port del Bukoleon per a rebre a Tirant a la terrassa de l'anomenada Casa de Justinià, que s'obria al mar de Màrmara. Desprès de desembarcar, la desfilada triomfal voreja la muralla per a dirigir-se a l'Augusteon, la plaça d'on partia la Mesè, la llarga avinguda que articulava l'entramat urbà i donava accés al palau a través d'un portal flanquejat per una "pinya tota d'or, d'alçària d'un home i molt grossa" fàcilment identificable amb la Porta de Bronze o Chalkee, un pòrtic cobert per un continu de voltes de canó que descansaven sobre enormes columnes simbòlicament esculpides (Mathews 2010: 18-24). Història, edificis, protocols bizantins eren ben coneguts, difosos per les cròniques de viatgers com Ramon Muntaner o Pero Tafur, que s'erigiren en fonts documentals de primera mà per a la fisonomia de Constantinoble (Riquer 1992: 161). 
Amb la ciutat alliberada arran del triomf, Tirant arriba al port on s'improvisa un pont de barques especialment construit per al desembarcament. L'escriptor cita un protocol habitual en les recepcions règies que ell mateix havia observat en l'entrada d'Alfons el Magnànim a Nàpols, el 8 de juliol de 1421 (Ryder 1992: 121-122). Amb tarimes de fusta cobertes per teles de seda brodades amb fils d'or i argent esteses sobre el pont, el cerimonial del triomf desvela la noció medieval de l'entitat urbana, és a saber, la percepció d'un àmbit mudable que incorpora a la seua aparença quotidiana el sentir ciutadà generant un entorn cultural obert a la sociabilitat (Zumthor 1994: 124-125). Els sentits del lector no descansen, la plaça davant el palau recoberta de teixits de vellut carmesí, les taules parades amb confits, l'urbs transformada per la música i les danses.

\section{La plaça en l'urbs medieval i el seu reflex a la novel la}

La plaça pública articula la vida social, troba a la novel la tota la seua significació com atribut de sociabilitat per excel lència del fenomen urbà, precisament l'aspecte que Martorell destaca en ella. La plaça es planteja com l'escenari privilegiat per a la manifestació del poder en la ciutat, com un espai extens, prest a transformar la seua fesomia per qualsevol esdeveniment (Zambrano 2000). En cap cas precisa la seua morfologia o el seu perfil arquitectònic, allò que subratlla és la seua condició com a centre de la vida política i espiritual de la comunitat. Serveix per a l'agrupació en les assemblees deliberatives, és l'espai de reunió on se celebren els convits de benvinguda, on Tirant convoca els habitants per fer el repartiment dels queviures. Patrimoni comunal i punt d'encontre, no es concreta a partir d'una dotació arquitectònica determinada, sinó que surt físicament de la confluència dels carrers principals. En un intent de definir-la, és potser la seua vocació pública la noció més apropiada, una idea que admet la multiplicitat d'usos que la caracteritza. El seu aspecte canvia en funció de l'ús que se'n faça d'ella. La descriu emparamentada en les cerimònies, presa pel bullici de veus, cants i sons d'instruments, coberta de teles de ras, seda i pedres precioses, creuada per taules repletes de viandes i confits. La plaça constitueix el cor de la vida urbana i varia amb ella al ritme dels esdeveniments. El mercat entapissat en Constantinoble es transforma en una mena de plaça de bous, una tradició mediterrània arrelada a València amb diverses variants que l'autor trau a col lació (Narbona 2003).

Arquitectures efímeres, tarimes, cadafals de fàcil i ràpid muntatge comporten una transformació profunda de la seua aparença: la ciutat convertida per uns dies en un espai teatral on totes les actuacions giren al voltant del protagonista (Ferrer 1992: 310). Martorell copia costums protocol làris de les entrades reials a València per enaltir el seu heroi i trasllada així la imatge de l'urbs abillada per a la festa. Gràcies a la inferència de significats al legòrics o místics i religiosos, aliens a l'essència pura del paisatge urbà, es revela una nova concepció de la ciutat, dispar i aliena a l'espai viscut diàriament. L'autor subratlla l'ús múltiple de la plaça que amb les celebracions cobra una nova dimensió, i l'espectacle cívic s'apodera d'un entorn que esdevé un escenari teatral extraordinari. L’urbs presta els espais a la sumptuositat «molt bella e gran», dominada espontàniament «per 
diverses maneres de solaços de balls e jocs». Les places són punts neuràlgics que permeten prendre el pols a la vida quotidiana.

A Constantinoble, després de l'alliberació de la amenaça turca, el rigor jeràrquic s’imposa en l'ordenació de l'espai, amb la taula imperial en el lloc preeminent, la resta de convidats distribuïts conforme al seu rang i els presoners seguts per terra. Es tracta de disposicions similars a les que corroboren cròniques com la de Muntaner amb motiu del convit per celebrar la coronació d'Alfons el Benigne, a Saragossa, en 1328 (Rubió 1985: 244-247).

La plaça és el punt de concentració festiva que convida a la complicitat, tot i que el protocol impose distàncies. El paisatge urbà canvia la seua aparença per assumir una nova funció narrativa, de manera que el revestiment d'edificis, places i carrers deslliura a aquests elements de les seus funcions habituals, per aparellar una ciutat ritual que és escenari del culte públic (Narbona 2017: 98-100). En les processions marxa el clergat amb les relíquies, els valors terrenals se sumen als espirituals sota una concepció cosmològica que permet identificar àmbits on sols una tènue línia s'interposava entre allò profà i allò diví (Huizinga 1984: 215-221).

\section{5.- La defensa de la ciutat: el castell i la muralla}

Vorejant tots aquests espais es troba la muralla, un element clau de protecció, que delimita l'entorn urbà i separa l'interior, altament valoritzat i ben definit, del territori exterior, freqüentment subordinat, constret a col laborar amb l'urbs, aportant-hi mà d'obra i productes, a més dotar-la de paisatge. La muralla comporta igualment una doble significació simbòlica de pertinença i identitat col lectiva (Le Goff 1989: 6-8).

Dos capítols de la novel la brinden ocasió per a analitzar com es concebien i quins són els aspectes significatius de la ciutat fortificada: el castell senyorial de Warwick i el santjoanista en Rodes, que plantegen a més la possibilitat d'examinar dos models diferents de fortificació.

\section{1.-E1 Comtat de Warwick. Un exemple de castell fortificat}

El paisatge urbà fortificat es presenta a Warwick dominat per un castell senyorial envoltat per les cases dels súbdits, artesans i comerciants encarregats del seu aprovisionament. El castell compta amb un sistema de fortificació propi, amb diverses dependències internes classificades en funció del seu ús. Una sala principal on s'exhibeix el tinell, amb vaixelles d'or i d'argent, on es munten les taules per a menjar i s'abillen les festes. La cuina i el rebost són àmbits domèstics la disposició dels quals recau en la senyora de la casa: a la novel la ofereixen pinzellades costumistes.

Està dotat d'una Sala del Consell, amb estrada per a presidir l'assemblea; les parets cobertes de tapissos brodats i una sala d'armes. Les habitacions dels comtes tenen gabinets privats adossats, on la comtessa guarda gelosament les armes personals del marit, «penjades, cobertes de domàs blanc 
i verd amb un lleó coronat». El castell compta amb un portal principal i un altre secret, «fals», en previsió d'emergències. Les torres mantenen una guarnició de vigies, comandats per un capità responsable dels torns de guàrdia. Els detalls donen la pauta dels costums i són els complements que aporten una concepció precisa de l'espai arquitectònic.

La panoràmica dels voltants mostra una vall extensa, sembrada de turons on el comte es retira a la contemplació amb hàbit de Sant Francesc, en una aillada ermita. Amb el retrat de la vellesa del cavaller, imatge estereotipada de l'anacoreta, Martorell descriu un ús freqüent en Europa en els segles XII al XV, documentat en el Regne de València, on les corrents eremites ocasionaren fundacions monàstiques a instàncies reials o aristocràtiques (Riquer 1990: 80). Bon reflex a la novel la és la promoció de la nova ermita per la comtessa, entre «una espesura d'arbres, una lúcida font, florides herbes i fornida de totes les coses necessàries per a la humanal vida». Identificada per Riquer (1984: 323) com l'ermita de Guy de Gliff, prop del castell de Warwick a Enstwistle, generosament dotada per Richard de Beauchamp, comte de Warwick, per a honrar la memòria del seu mític avantpassat.

\subsection{Rodes}

L'escrutini més exhaustiu de la muralla arriba amb la crida d'auxili del Gran Mestre de l'Orde de l'Hospital de Rodes, que du al protagonista a demostrar la seua vàlua com cavaller i capità, comandant d'un exèrcit (Riquer 1979: 43-44). Compromès amb la veracitat, l'escriptor proporciona antecedents geogràfics i històrics del nou escenari cap a on es dirigeix la ficció. Illa mediterrània, a Rodes conflueixen cavallers de tots els regnes de l'Occident europeu, i es descrita amb nuclis de població dispersos, associats i dependents del nucli principal on s'alça el castell i la ciutat. La seua condició estratègica fa de l'illa un territori abellidor per al trànsit marítim i el comerç, amb l'atractiu afegit de la fertilitat d'una terra fructífera i abundant en mercaderies. L'orografia de l'illa s'entreveu rocosa i accidentada, amb depressions acusades per les seues reduïdes dimensions. Tirant desembarca en un arenal proper a les muralles. Pròxim a la platja s'eleva el castell, i en la part oposada es troba el port, on s'han concentrat les naus enemigues. Amb poques precisions, Martorell dibuixa un plànol geogràfic exacte al temps que fa explícita la posició de les parts implicades en escena (Durán 2009).

Rodes és una ciutat emmurallada per un sistema de murs concèntrics que permeten el control dels accessos al pati, amb un primer portal de majors dimensions i uns altres dos menors per estrènyer el cèrcol, als quals s'afegeixen, encara, diverses torres (Cairns 1999: 31-32). Es tracta d'un disseny urbanístic pensat per dominar el territori, que trasllada la realitat urbanística de l'urbs i l'extensió que abastà el perímetre emmurallat en la hospitalera Rodes (Jehel i Racinet 1999: 103-105).

Aquesta exaltació de la muralla denuncia la situació extrema de la ciutat assetjada. El portal permet l'accés directe al pati central, al voltant del qual es distribueixen les diferents dependències. La torre de l'homenatge és l'emblema de tot l'espai i és símbol de poder. Variant de la tipologia 
de castell feudal, s'adapta a las particularitats de la vida comunal amb dotacions específiques per a les necessitats litúrgiques. Així, un concepte equivalent a la sala del Consell dels àmbits senyorials és la Sala Capitular per a les deliberacions relatives a la jurisdicció i l'administració de l'orde militar, estança de morfologia no precisada, però que orienta indefectiblement cap a un àmbit monàstic.

\section{La descripció de València, model de lloança urbana}

El recés en la marxa dels conflictes brinda l'oportunitat a Martorell d'inserir l'única referència directa a València, a través d'una lloança que constitueix una descripció reveladora de les seues consideracions estètiques del paisatge urbà. Obviada conscienciosament en la narració, fins i tot en aquesta apel lació directa als seus orígens prima la voluntat d'eludir mencionar la Corona de Aragó i localitza València «en Espanya la baixa», traslluint els canvis polítics produitts arran de l'entronització de la Dinastia Trastàmara.

No és menester reproduir-la, però si que analitzarem el seu contingut per a observar la intencionalitat estètica, perquè les visiones de les ciutats descrites en la novel la es comprenen a partir d'aquesta ressenya que condensa tots els ingredients de la descriptio civitatis, la tradició literària gestada en la laudatio característica del relat hagiogràfic (Zumthor 1994: 108-115). És una referencia especialment interessant en entrar en relació amb la cèlebre Laus Valentiae que el franciscà Francesc Eiximenis va incloure en el Regiment de la cosa pública (1385-1386) dedicat als Jurats de València. El to d'exaltació de l'urbs, «de tots béns fructífera», és el motiu que guia l'elogi, una temprança que es deu a l'especial emplaçament de València respecte al paradís terrestre, «com l'esfera del sol dóna en paradís terrenal, qui reverbera en la ciutat e regne de València...e d'ací li ve tot lo bé que té», emplaçat a l'altra banda del món, com explica l'autor del Polycronicon (Hauf 2008: 1185). També Eiximenis compara València amb el paradís terrenal, «que si paradís és en la terra, que en regne de València és», perquè la seua bellesa prové de Deu, de manera que se sembla al paradís en virtut de l'excel lència i la bondat de les seues coses naturals.

L'escriptor lloa una agricultura «molt abundosa», els excedents de la qual proporcionen la base sòlida de l'expansió comercial «d'on se traen més mercaderies que de ciutat que en lo món sia, exceptat espècies». La productivitat de la terra i la condició portuària són agents de bellesa, captats com a factors principals en l'exaltació del territori. Aquesta circumstància és ressaltada igualment per Eiximenis, qui considera que la ciutat del Túria és la metàfora perfecta del paradís, perquè la seua prosperitat atrau els visitants, propicia el caràcter alegre i vital dels seus habitants, que tant complau al foraster, afavorint-ne el comerç. El franciscà s'entreté a descriure una prosperitat que justifica en les trenta-dues benediccions que ha rebut la terra valenciana, és a dir, la fertilitat d'una planícia purificada pels vents, banyada per la mar i per nombrosos rius i fonts que afavoreixen el conreu i l'abundància d'aliments i de llenya. 
En les seues argumentacions, Eiximenis fa èmfasi en la bellesa identificada amb la virtut, la pulcritud i la salubritat. Sempre sota la influència agustiniana, Eiximenis justifica les seues raons, no tant per la seua generositat com per la seua bellesa, perquè en el pulchrum es troben perfectament harmonitzades la veritat, la bondat i la unitat (Vilanou 2012). El seu ideal de ciutat s'orquestra, per consegüent, a la manera d'una projecció estètica bella, on la virtut sotmet el pecat. Igualment, Martorell valora entre les seues bondats la fertilitat de la regió, en descriure «los monts e fort belles valls, fèrtils e de fort agradosa vista» i recorda que València fou construïda en «pròspera Fortuna», reprenent així les condicions de la ciutat ideal eiximeniana en la suma de factors simbòlics i topogràfics, respecte a la seua orientació i disposició (Corral 1987).

La seua «pròspera Fortuna» prové de la dignitat dels pobladors, gentilhomes «valentíssims cavallers, de bona conversació». Imprecació purament tòpica a la Fortuna, amb què inserta una noció essencial en limitar els efectes d'atzar que hom pot ja dominar gràcies a la dignitat de la virtut cavalleresca. Noció on es pot percebre el batec humanista que venç l'amenaça dels capricis astrològics mitjançant la Fe i oposa als infortunis la benaventurança providencial (Manzanaro 1998: 138).

En centrar els seus discursos en l'home, un dels elements consubstancials en la ciutat és la congregació concordant de «persones adjundants la una a l'altra segons llurs necessitats» que Eiximenis destaca al Regiment, subratllant la necessària harmonia social que deu prevaldre entre els interessos individuals i les funcions que cada ciutadà ha de complir (Vila 1984: 73-75). El franciscà entén i accepta el canvi produït en la societat urbana i la importància del progrés mercantil en l'ordre civil, per això l'abundància i la varietat de les seues gents és un símptoma evident de prosperitat. Aquest és precisament un dels criteris emprats per Martorell per qualificar una urbs de rica i afortunada, perquè la pluralitat és reflex d'una societat benestant, activa i virtuosa. Aquesta societat urbana modificarà la concepció de l'home i la vida en el trànsit del món medieval al modern. Amb l'acceptació dels valors de les noves forces econòmiques i socials, ambdós autors s'alineen junt a l'estirp dels grans utopistes del primer Renaixement, com Campanella, Tomàs Moro o Maquiavel, que assumiren les profundes transformacions succeïdes entre el 1350 i el 1550, i que comportaren un canvi essencial en la imatge i en la concepció de la ciutat. Arran de l'ascens de la nova classe burgesa i el rencontre amb el pensament de sant Agustí, l'humanisme del segle XIV obri de nou el debat entre la ciutat ideal-celestial i la ciutat real-terrena, que enfronta dos ideals filosòfics distints, el neoplatonisme i el neoaristotelisme (Corral 1987).

Eiximenis és un ferm defensor de l'urbs en ésser la millor referència de la presència de Déu i l'àmbit idoni per al perfeccionament de l'Estat. En el seu projecte de ciutat ideal, imprimeix una empremta reformista que augura en la virtut de la nova societat urbana el sorgiment d'uns valores que veten els excessos dels governants i recriminen la conducta inapropiada dels eclesiàstics que no actuen conforme al seu estament. Atesa la seua preocupació pel bon govern, el seu interés per la ciutat bascula entre dues cosmovisions: la baix-medieval i la humanista (Vila 1984: 67-68). Tres elements caracteritzen la percepció de l'urbs d'ambdós: una nova ètica, una estètica renovadora i la 
preeminència dels valors personals basats en la glòria, pivot de l'humanisme. Eiximenis destaca el progrés, l'impuls de les arts i, com Martorell, xifra la noblesa en la cavalleria. En el nivell simbòlic ambdós accentuen en la fisonomia de l'urbs la importància de les muralles, expressió d'autonomia i claus per a la seua defensa. Un altre element substancial en la vida urbana són les seues places, on convergeixen els múltiples significats del pols urbà.

Martorell finalitza el seu elogi amb una apel lació reveladora als astres, en incidir en la temprança de la terra «com l'esfera del sol dóna en paradís terrenal, qui reverbera en la ciutat e regne de València...e d'ací li ve tot lo bé que té». El recurs a aquest tipus d'explicacions de caràcter astrològic es troba també en els raonaments eiximenians, perquè la consulta als astres és imprescindible a l'hora de establir els criteris per a la fundació d'una urbs, ja que «per ignorància de astrologia són moltes ciutats infortunades e per bon esguard celestial són moltes diversament fortunades e de gran duració». Riquer esclareix la inspiració per a aquests discursos en una base astrològica elemental estesa a València des de la dominació musulmana. Martorell trau a col lació l'afany dels seus coetanis per la consulta als astres i conclou convenint amb l'astrologia ptolemaica que ubica València en el clima quart i a la quarta esfera del sol (Riquer 1984: 221-222). Els textos àrabs expliquen la lluminositat del cel valencià pel reflex del sol sobre l'Albufera -i ben conegudes eren les lloances del poeta del segle XII, al-Rusafí, en la seua qasida dedicada a València (Huici 1969: 38).

En la seua referència condensa els paradigmes essencials de la ciutat, la influència dels voltants i la importància de les comunicacions, la confluència de gents de diverses condicions i procedència, la significació de la connotació particular a la identitat urbana. Així mateix, la identificació d'una sèrie d'espais de poder i de sociabilitat urbana, com són el palau o el castell, la catedral, la plaça i la muralla.

\section{Conclusions}

El Tirant es fruit d'experiències personals del novel lista que hi trasllada l'ambient, les passions i el temperament d'una època, lliure d'alterar la història i la geografia, per aconseguir inocular els secrets i els fantasmes que l'envolten. Martorell s'esforça per reflectir la varietat colorista del món que té al voltant en els petits detalls, conscient que constitueixen la clau per situar la ficció en el marc d'una realitat creïble. En aquest sentit, el transcórrer del temps, puntualitzat en cada jornada, és aprofitat per traçar una mena de dietari implícit que permet ajustar el context espai-temps a l'experiència ordinària. L'evocació ambiental és tan directa que s'apodera dels sentits i la vivacitat de les escenes neutralitza qualsevol dubte sobre la veracitat d'una ficció que és assumida sense rèmora.

Crea una intriga on veritat i mentida es fonen amb sorprenent harmonia, per submergir el lector en una maquinació en la qual arriba fins i tot a perdre la noció entre la realitat i la quimera. Resulta inútil tractar de desxifrar la veracitat de les dades, ja que la representació geogràfica està tan ben 
travada, mitjançant agents complementaris com l'orografia, el clima, la història o els costums de cada territori, que perd relleu l'intent per discriminar la existència de cada una de les ciutats mencionades. Conscient que la novel la li pertany, l'escriptor baralla ciutats reals amb altres inventades, però tan ajustades a referents verídics que la insistència en la validació perd importància, a favor de la impressió general. Introduïdes aleatòriament, mai frustren el periple per Europa i pel nord d’Àfrica, sotmeses com la resta dels components de la intriga, a la mescla d'intel ligència $i$ fantasia que caracteritza la «novel la total» (Escartí 2005: 7-19).

Just quan l'Humanisme inicia la batalla davant el folklorisme i el naturalisme franciscà divulga una visió més racionalista, es descobreix en l'esperit realista del Tirant lo Blanc un retrat complet de l'època en què fou escrita, on els miratges són substituïts per una sòlida dosi d'allò que s'entén per versemblança en literatura, fenomen que es prodiga paral lelament en els diferents camps de la creació artística. Martorell crea un univers d'aventures que ens du a explorar pràcticament tota Europa i l'espai mediterrani, en un complot d'entelèquia i certesa que no arriba mai a dissipar la sensació de veracitat. Germanitzada per la coherència de cronologies i espais geogràfics familiars al lector i per uns personatges fets a mesura humana, ofereix «un tesoro de contento y una mina de pasatiempos» que permet somniar, deixar-se seduir per una il lusió cenyida per eixe pols vitalista tan celebrat pel sacerdot cervantí, perquè «aquí comen los cavalleros, y duermen y mueren en sus camas, y hazen testamento antes de su muerte, con otras cosas de que todos los demás libros deste género carecen», una prudència que rendeix al lector als peus de la faula. 
Teresa Izquierdo Aranda. Les ciutats del cavaller Martorell. La representació de l'urbs en el Tirant lo Blanc

\section{Bibliografia}

Badia, L. (1993) «El Tirant en la tardor medieval catalana». Actes de Symposion Tirant lo Blanc, Barcelona, Quaderns Crema, pp. 35- 97.

Boucheron, P., Menjot, D. i Boone, M. (2010) «La Ciudad medieval» dins Pinol, J. L. (dir.) Historia de la Europa urbana, València, Universitat de València, 2 vol.

Cairns, C. (1999) Los castillos medievales, Madrid, Akal.

Corral Lafuente, J. L. (1987) «Significado y símbolo de la ciudad medieval: elementos semióticos en el mundo urbano de Europa occidental (1350-1550)», Revista de Historia Jerónimo Zurita, 56, pp. 131-160.

Durán Duelt, D. (2009) «Presencia hispánica en Rodas: A propósito del Albergue de la Lengua de España», Memòries de la Reial Acadèmia Mallorquina d'Estudis Genealògics, Heràldics i Històrics, 19, pp. $97-112$.

Dutour T. (2004) La ciudad medieval: orígenes y triunfo de la Europa urbana, Barcelona, Paidós.

Eiximenis, F. (1986) Dotzé llibre del Crestià. X. Renedo (ed.). Girona, Col legi Universitari de Girona.

—. (1980.) Regiment de la cosa pública. D. de Molins de Rei (ed.). Barcelona, Barcino.

Ferrer Valls, T. (1992) «El espectáculo profano en la Edad Media: espacio escénico y escenografía» dins Beltrán, R., Canet, J. L.i Sirera, J. L.(eds.) Historias y ficciones: coloquio sobre la literatura del siglo XV, València, Universitat de València. Departament de Filologia Espanyola, pp. 307-322.

Gadea, F. i Cònsul (1990) Tirant lo Blanc. Guia de lectura, Barcelona, Edicions de la Magrana S.A.

Giner i Llorens, J., \& Montesinos i Martínez, J. \& Martí i Ferrando, J. (1990) Tirant $i$ el seu temps, València, Direcció General de Centres i Promoció Educativa, Servei de Programes d’Alumnes.

Huici Miranda, A. (1969-1970) Historia musulmana de Valencia y su región: novedades y rectificaciones, València, Ajuntament de València.

Huizinga, J. (1984) El otoño de la Edad Media, Alianza Universidad, Madrid.

Izquierdo Aranda, T. (2013) «Un palacio para un héroe: la representación del Sagrado Palacio Imperial de Constantinopla en el Tirant lo Blanc», Anales de Historia del Arte, 23, pp. 487- 497.

Jehel, G. i Racinet, P. (1999) La ciudad medieval: del Occidente cristiano al Oriente musulmán (siglos V-XV), Barcelona, Omega.

Krautheimer, R. (1984) Arquitectura paleocristiana y bizantina, Madrid, Cátedra.

Le Goff, J. (1989) «Construzione e distruzione della città murata» dins De Seta, C., La città e le mura, Roma, Laterza. 
Teresa Izquierdo Aranda. Les ciutats del cavaller Martorell. La representació de l'urbs en el Tirant lo Blanc

López Elum, P. (2002) Los castillos valencianos en la Edad Media: materiales y técnicas constructivas, València, Biblioteca Valenciana.

Manzanaro Blasco, J. M (1998) Fortuna en el Tirant lo Blanch i el Curial e Güelfa, Alacant, Universitat d'Alacant.

Martorell, J. \& Galba, M. J. (1984-1985) Tirant lo Blanc. M. de Riquer (ed.). Barcelona: Edicions 62.

Martorell, J. (2005) Tirant to Blanc. A. Hauf \& A. I. Peirats \& V. J. Escartí (eds.). València, Tirant lo Blanc.

—. Tirant lo Blanc. Hauf, A., (ed.) (2008), València, Tirant lo Blanc.

Mathews, T. F. (2010) Byzantium: from antiquity to the Renaissance, London, Yale University Press.

Narbona Vizcaíno, R. (2003) Memorias de la ciudad. Ceremonias, creencias y costumbres en la historia de Valencia, València, Ajuntament de València.

- (2017) La ciudad y la fiesta: cultura de la representación en la sociedad medieval (siglos XIII-XV), Madrid, Síntesis.

Oleza Simó, J. (1992) «Tirant lo Blanc y la ansiedad de ficción del caballero Martorell» dins Beltrán, R. \& CanetJ.L. \& Sirera, J.L. (eds.) Historias y ficciones: coloquio sobre la literatura del siglo XV, València. Universitat de València. Departament de Filologia Espanyola, pp. 323-335.

Riquer, M. de (1979) Tirant lo Blanc i altres escrits de Joanot Martorell, Barcelona, Seix Barral.

——. (1990) Aproximació al Tirant lo Blanc, Barcelona, Quaderns Crema.

- (1992) Tirant lo blanc, novela de bistoria y de ficción, Barcelona, Sirmio.

Roca Traver, F. A. (1952) Un siglo de vida mudéjar en la Valencia medieval (1238-1338), Saragossa, Escuela de Estudios Medievales.

Rubiera, M. J. (1993) Tirant contra el Islam, Alacant, Aitana.

Rubió i Balaguer, J. (1985) Vida española en la época gótica, Barcelona, Departament de Cultura de la Generalitat de Catalunya/ Publicacions de l'Abadia de Monserrat.

Ryder A. (1992) Alfonso el Magnánimo. Rey de Aragón, Nápoles y Sicilia. 1396-1458, València, Edicions Alfons el Magnànim/ Institut Valencià d'Estudis i Investigació.

Vargas Llosa, M. (1991) Carta de batalla por Tirant lo Blanc, Barcelona, Seix Barral.

Vila, S. (1984) La ciudad de Eiximenis: un proyecto teórico de urbanismo en el siglo XIV, València, Diputació Provincial de València.

Vilanou Torrano, C. (2012) «El Humanismo de Eiximenis: saber, ciudad y cortesía», Historia de la educación, 31, pp. 135-163.

Villalmanzo, J. \& Chiner, J. J. (1992) La pluma y la espada: estudio documental sobre Joanot Martorell y su 
Teresa Izquierdo Aranda. Les ciutats del cavaller Martorell. La representació de l'urbs en el Tirant lo Blanc

familia (1373-1483), València, Ajutament de València.

Zambrano, F. (2000): La ciudad en la historia. La ciudad, hábitat de diversidad y complejidad. Bogotà, Universidad Nacional de Colombia.

Zumthor, P. (1994) La medida del mundo. Representación del espacio en la Edad Media, Madrid, Ediciones Cátedra. 